correspond in every way to the 'typical' form ; they differ, however, in their action on some of the other carbohydrates.

Much controversy has arisen as to the part played by $B$. granulosis in the aetiology of trachoma; moreover, other micro organisms have been isolated and put forward as aetiological factors. Again, various authors have maintained that the condition is due to a virus, to diet deficiency and lastly that it is an expression of allergy.

With these views, however, this paper is not concerned. In our introductory remarks it was clearly indicated that considerable divergence existed in the results of those authors who had carried out work along lines similar to that of Noguchi and our investigation was undertaken merely to ascertain whether $B$. granulosis was present or not in cases of trachoma occurring in Glasgow.

We suggest that some of the discrepancies in the results obtained by various workers have been due to their not having allowed sufficient time for growth to have progressed to the extent of producing visible 'colonies' before pronouncing that the microorganism in question was not present in the material examined. Again, some of these investigators may not have been conversant with the inhibiting action of cocaine on the growth of $B$. granulosis.

Lastly, the importance of immediate inoculation of the media, the keeping of the inoculated plates at room temperature and of maintaining a sufficiently moist surface should be emphasised.

\title{
Conclusion
}

An investigation has been carried out in order to ascertain whether B. granulosis, Noguchi, occurs in cases of trachoma in Glasgow. The results obtained, show that this organism is present in a proportion of these cases.

\section{THE WATER-BINDING OF THE OPTIC NERVE AND OF ITS SHEATHS}

BY

J. A. van Heuven and P. F. Fischer

UTRECHT

After our paper on the water-binding of the retina some interesting investigations have been published on the genesis of papilloedema, and it seemed to be of some importance that similar researches on nervous tissues should be done. For these reasons we continued our experiments. 
This time we took the optic nerve instead of the retina and worked very much after the same scheme. In doing so we investigated first the capacity, then the intensity, and finally the form of the water-binding.

Again we used ox-eyes, obtained as fresh as possible from the slaughter-house, which were brought to our laboratory still embedded in the orbits. The optic nerve and its sheaths were separated from all other tissues, after which the coat of sheaths was incised by means of a pair of scissors as far as the entrance of the optic nerve in the globe, and finally the optic nerve was separated from the globe in such a manner that the papilla remained attached to the optic nerve.

Now it appears to be of practical importance that as far as possible pieces of the optic nerve of the same size should be used. To get these we made use of a little cutting machine consisting of two glass tubes placed end to end and separated only by a small slit, sufficiently wide to allow a razor blade to be used. The glass tubes were mounted on a wooden base and contained a lumen which allowed the optic nerve to pass through.

By using this instrument it was possible to get pieces of optic nerve, all of which were $2 \mathrm{~mm}$. long. As a rule, 10 to 15 of these small pieces were taken from each optic nerve.

These small pieces of optic nerve were weighed, then put in different liquids and then weighed again. From the difference in weight the absorption or the loss of water could be calculated in percentage.

The first liquid to be used was distilled water. From numerous experiments we learned that after one hour there was found an average increase in weight of 77 per cent.; after three hours the average increase in weight was 90 per cent., and after 24 hours 160 per cent. Thus it appears that the absorption in distilled water of the optic nerve is many times greater than that of the retina. Further experiments showed that this gain in weight of the optic nerve in water was, in fact, only dependent upon the absorption of water. Practically nothing was dissolved in the water, only after 24 hours the $\mathrm{Cl}$ reaction was slightly positive.

Looking at the optic nerve from an anatomical point of view we found that the further the small piece of optic nerve was taken away from the globe the greater the absorption of water appeared to be. Further numerous researches showed that in fresh condition the optic nerve contains more water near the globe than at some distance from the globe. As a matter of fact, the papilla of the optic nerve contains the greatest quantity of water. Though the differences are not great, they are found to be regular. About 
half way the water percentage of the optic nerve is about $\mathbf{7 4}$ per cent.

If we take our small pieces of optic nerve and put them in acids instead of in water we get the following results : Schedule I shows the percentage of increase in weight, if we leave them in the liquid for three hours.

SCHEDULE I

\begin{tabular}{lll|c|c|c|c|c|c}
\hline & & $\mathrm{N}$ & $\mathrm{N} / 2$ & $\mathrm{~N} / 10$ & $\mathrm{~N} / 100$ & $\mathrm{~N} / 1000$ & $\mathrm{~N} / 10000$ \\
\hline Hydrochloric acid & $\ldots$ & +19 & +29 & +47 & +48 & +56 & +66 \\
Sulphuric acid & $\ldots$ & $\ldots$ & +20 & +24 & +25 & +37 & +45 & +54 \\
Nitric acid & $\ldots$ & $\ldots$ & +18 & +18 & +36 & +37 & +42 & +49 \\
Acetic acid & $\ldots$ & $\ldots$ & +43 & +44 & +42 & +36 & +34 & +33 \\
Lactic acid & $\ldots$ & $\ldots$ & +82 & +71 & +65 & +46 & +35 & +34 \\
Citric acid & $\ldots$ & $\ldots$ & +86 & +78 & +67 & +53 & +48 & +40 \\
\hline
\end{tabular}

This schedule shows that the water absorption in acids is lower than that in distilled water. So the water absorption in acid solutions is retarded in comparison with that in pure water. During the first 12 hours this is the case in all acids. If the pieces of optic nerve are left in solutions of organic acids for over 12 hours the water absorption becomes greater than that in pure water. This means that in acids the water absorption is a slow process. Furthermore, it is clear from schedule $I$ that in increasing concentrations the water absorption is retarded by mineral acids and promoted by organic acids. Equal normality does not mean equal water absorption.

We did not succeed in getting reliable figures representing the water absorption of small pieces of optic nerve in alkalies. The reason for this is clear if one looks at those pieces of optic nerve which have remained in an alkaline solution for more than one hour. A change has taken place in the pieces of optic nerve very similar to that which we found in the pieces of retina (Brit. Jl. of Ophthal., p. 390, July, 1935). They show a lengthening on both ends, whilst the middle part remained either almost the same or even shrunk; after this they dissolved, sometimes in the form of long threads. This change is due to a water absorption which surpasses many times that in pure water. So we are safe in saying that the water absorption by the optic nerve is promoted intensively in alkalies. Furthermore, in alkaline solutions the same rule holds 
good as in acids, i.e., that equal concentration does not mean equal water absorption.

Schedule II shows the percentage of increase in weight of small pieces of optic nerve which remained for three hours in solutions of salts.

SCHEDULE II

\begin{tabular}{lll|l|l|l|l}
\hline & & & $\mathrm{m}$ & $\mathrm{m} / 10$ & $\mathrm{~m} / 100$ & $\mathrm{~m} / 1000$ \\
\cline { 2 - 6 } Na-cyanide & $\ldots$ & $\ldots$ & +17 & +39 & +51 & +69 \\
Na-rhodanide & $\ldots$ & $\ldots$ & +30 & +32 & +35 & +41 \\
Na-nitrate & $\ldots$ & $\ldots$ & +19 & +34 & +38 & +38 \\
Na-iodide & $\ldots$ & $\ldots$ & +17 & +16 & +21 & +28 \\
Na-bromide & $\ldots$ & $\ldots$ & +21 & +41 & +55 & +72 \\
Na-tartrate & $\ldots$ & $\ldots$ & -1 & +17 & +30 & +40 \\
Na-phosphate & $\ldots$ & $\ldots$ & -3 & +15 & +27 & +32 \\
Na-sulphate & $\ldots$ & $\ldots$ & -10 & +26 & +41 & +47 \\
Na-citrate & $\ldots$ & $\ldots$ & -12 & +15 & +29 & +39
\end{tabular}

Generally speaking, we may say that equimolar solutions show different effects. The water absorption is retarded in salt solutions; this retardation is more pronounced the stronger the solution.

If we take anelectrolytes instead of salts similar results are obtained.

From the behaviour of small pieces of optic nerve in solutions of acids, alkalies, salts and anelectrolytes may be concluded that their absorption of water must be looked upon as a real swelling, similar to what we have found in the retina.

Moreover, a comparison between the absorption of water by the retina and by the optic nerve shows that the capacity of the water-binding of the optic nerve is much greater than that of the retina.

Afterwards we tried to get some figures showing the intensity of the water-binding of the optic nerve. For this purpose we studied first the rapidity of the swelling. We made these experiments in the same way as we have done with the retina on a previous occasion in various bathing liquids. Here follow the figures for acetone and urea : 
SChedule III-CONCENTRATION OF ACETONE

\begin{tabular}{rllll|c|c|c|c|c}
\multicolumn{3}{c}{ Time in minutes } & $\begin{array}{c}10 \\
\text { per cent. }\end{array}$ & $\begin{array}{c}20 \\
\text { per cent. }\end{array}$ & $\begin{array}{c}30 \\
\text { per cent. }\end{array}$ & $\begin{array}{c}40 \\
\text { per cent. }\end{array}$ & $\begin{array}{c}50 \\
\text { per cent. }\end{array}$ \\
\hline $1^{\prime}$ & $\ldots$ & $\ldots$ & $\ldots$ & $\ldots$ & +10 & +15 & +17 & +11 & +6 \\
$5^{\prime}$ & $\ldots$ & $\ldots$ & $\ldots$ & $\ldots$ & +12 & +17 & +18 & +12 & +5 \\
$10^{\prime}$ & $\ldots$ & $\ldots$ & $\ldots$ & $\ldots$ & +12 & +18 & +19 & +7 & +5 \\
$60^{\prime}$ & $\ldots$ & $\ldots$ & $\ldots$ & $\ldots$ & +29 & +24 & +26 & +8 & +4 \\
\hline
\end{tabular}

A comparison of these with the corresponding figure of the retina shows that the optic nerve has the possibility of a quicker and more intensive swelling than the retina. In conditions of concentrations and time in which the retina loses water the optic nerve is still capable of absorbing water.

SCHEDULE IV-CONCENTRATION OF UREA

\begin{tabular}{|c|c|c|c|c|c|c|c|c|c|}
\hline \multicolumn{5}{|c|}{ Time in minutes } & $\begin{array}{c}10 \\
\text { per cent. }\end{array}$ & $\begin{array}{c}20 \\
\text { per cent. }\end{array}$ & $\begin{array}{c}30 \\
\text { per cent. }\end{array}$ & $\begin{array}{c}40 \\
\text { per cent. }\end{array}$ & $\begin{array}{c}50 \\
\text { per cent. }\end{array}$ \\
\hline $1^{\prime}$ & $\ldots$ & $\ldots$ & $\ldots$ & $\ldots$ & +8 & +13 & +10 & +10 & +16 \\
\hline $5^{\prime}$ & $\ldots$ & $\ldots$ & $\ldots$ & $\ldots$ & +11 & +9 & +11 & +12 & +13 \\
\hline $10^{\prime}$ & $\ldots$ & $\ldots$ & $\ldots$ & $\ldots$ & +14 & +12 & +12 & +17 & +15 \\
\hline $60^{\prime}$ & $\ldots$ & $\ldots$ & $\ldots$ & $\ldots$ & +20 & +24 & +26 & +34 & +29 \\
\hline
\end{tabular}

This shows that in urea in any condition of time and concentration the optic nerve absorbs water. Formerly we found that pieces of retina lose water when they are placed in solutions of urea for a short time or in a solution of high concentration. It is now demonstrated that the optic nerve has a greater tendency and potentiality to absorb water than the retina.

Furthermore, we have investigated the change of density in relation to the change in the water-percentage. We used the same method as before in our paper on the retina. This time, however, mercury was used as a liquid, as in both toluol and xylol the weight of the little pieces of optic nerve was changed.

Fig. 1 shows the change in specific weight in relation to the percentage of water. If the percentage of water increases the density is changed regularly, but slowly in comparison with the retina. Both in the retina and in the optic nerve the water-binding is the same in all stages, there are only quantitative differences. 
Water-Binding of Optic Nerve and its Sheaths 209

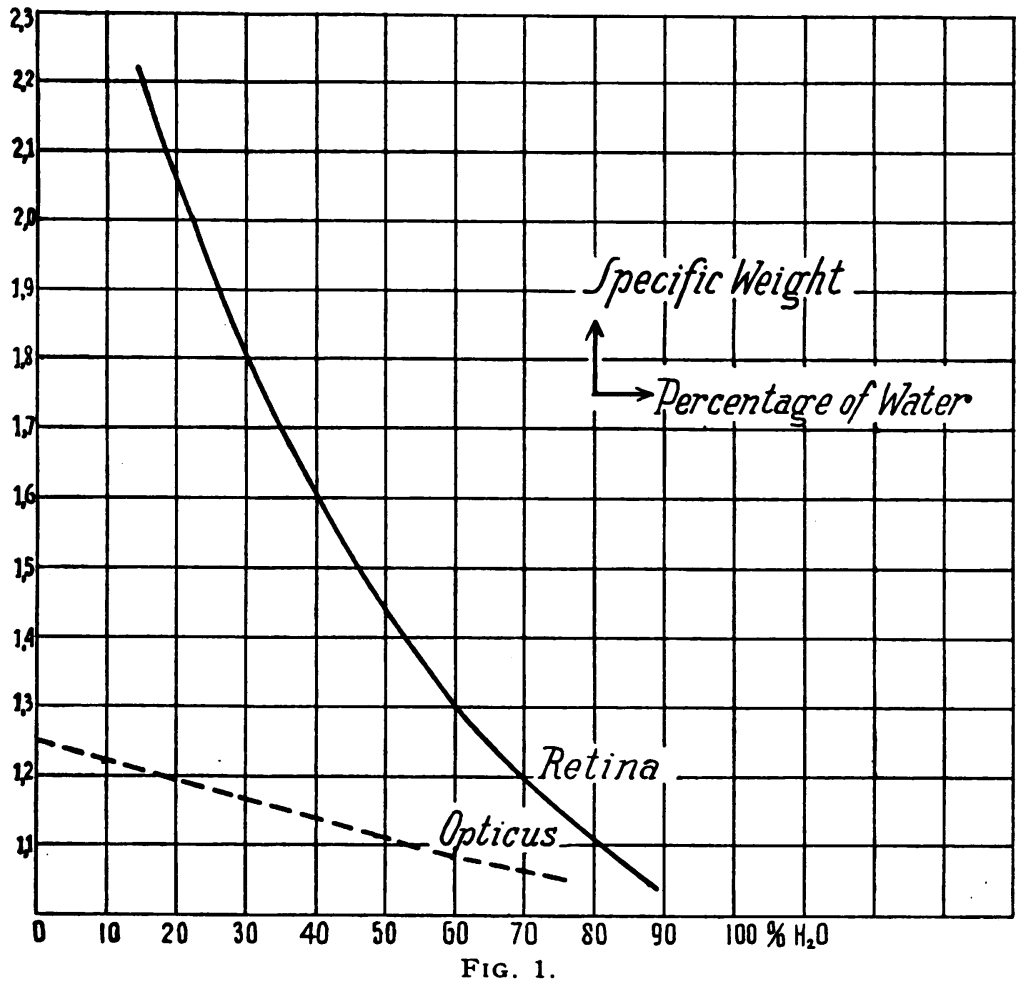

If the percentage of water decreases, the specific weight increases; if the percentage of water increases we get a relative diminution of the volume. This is smaller in the case of the optic nerve than in the retina.

Schedule V shows the rapidity of the loss of water in solutions of acetone of 75 per cent. and of 100 per cent.

Schedule V

\begin{tabular}{|c|c|c|c|c|c|c|c|}
\hline & & & & 75 per & Acetone & 100 per & Acetone \\
\hline & Cime & $\mathrm{mi}$ & & Loss of & Percentage & Loss of & Percentage \\
\hline $1^{\prime}$ & ... & ... & $\ldots$ & -2 & 71 & -8 & 76 \\
\hline $5^{\prime}$ & ... & ... & $\ldots$ & -1 & 70 & -3 & 68 \\
\hline $10^{\prime}$ & ... & ... & $\ldots$ & -3 & 68 & -15 & 72 \\
\hline $60^{\prime}$ & $\ldots$ & $\ldots$ & ... & -5 & 73 & -22 & 73 \\
\hline
\end{tabular}


It appears to follow that in the optic nerve only a relatively small quantity of water, namely, about $1 / 3$, is not colloid-bound. This is remarkable as in the retina all the water is free. Finally, we have tried to get an impression of the rapidity of the loss of water by drying small pieces of optic nerve at a temperature of $37^{\circ} \mathrm{C}$. After 19 hours the optic nerve reached a constant weight, i.e., in this way the optic nerve behaves exactly the same as the retina.

After the optic nerve we took its sheaths separately and performed precisely the same researches on them. We can summarize the results very briefly by saying that the sheaths of the optic nerve possess the same water-binding as the sclera.

This means that the sheaths of the optic nerve show swelling. This swelling is greatest in acids, in water it is little and in alkalies it is much less than it is in acids. The capacity of the water-binding is considerable, much greater than that of the optic nerve, while the intensity is much less than that of the optic nerve and also than that of the retina. The manner of the waterbinding of the sheaths of the optic nerve is different from that of the optic nerve and of the retina.

Generally speaking, we may summarize as follows :-Retina, optic nerve and its sheaths are tissues which have the possibility of swelling. In their absorption of water they differ essentially and their behaviour in water is even opposite to each other. Circumstances which promote the absorption of water by the optic nerve, cause, at the same time, a loss of water from its sheaths. Conditions which are able to change the percentage of water of the optic nerve are without significance for the retina, and vice versa. This different behaviour of tissues which are so closely situated next to each other cannot remain without clinical significance and without clinical manifestations.

Different authors as a matter of fact have already assigned to the power of water-binding of the optic nerve an important rôle : in a discussion during the year 1930, Marchesani stated that according to researches of Spatz and himself, atrophia cerebri senilis was caused by a decrease in the power of water-binding of the brain. The optic nerve being part of the brain has to share these changes.

Marchesani made the following demonstration. He took a cat and injected in its right carotid artery pure water and in its left carotid artery a solution of 10 per cent. $\mathrm{NaCl}$, both under the same pressure. The right part of the brain and the papilla of the right eye swelled, while at the same time the left part of the brain and the papilla of the left eye shrunk. The latter is shown by an excavation of the left papilla.

In 1934 Marchesani again stated that in 120 brains, still in 
connection with their own optic nerves he always found a parallelism between the swelling of the brain and the papilloedema. Only when after an operation the swelling of the brain subsided no papilloedema could be demonstrated. In every case it could be demonstrated that the swelling of the brain had been previous to the papilloedema. Marchesani has studied this subject from a pathologico-anatomical point of view, not from a physico-chemical one. But his macroscopical and microscopical pictures convinced him that the swelling which was shown, should be considered as a real swelling not as a swelling in the sense of oedema. He rather looks upon oedema as being a process of opposite character to swelling of the brain and papilloedema, no free liquid in the tissues is found, but ganglionic degeneration of the nerve fibres, big and pale nuclei of glia cells and clasmatodendrosis. It seems to be important that he was able to prove that the borders between ectodermal and mesodermal tissues show this increase in water absorption very clearly. This is in agreement with us, namely that the water absorption of the optic nerve and the retina is quite different from that of the sheaths of the optic nerve. Finally Marchesani points out that a direct comparison can be made between papilloedema and the " Zysternenverquellung " of Spatz. Namely, the brain tissue swells everywhere there where it is able to swell. Thus in the first place there is a swelling in the spaces filled with liquor ("Zysternen"). In a similar way the optic nerve swells on every spot where it is not confined bv inflexible tissue i.e., not in the sclerotic canal and not in the optic foramen, but it swells protruding into the globe.

These anatomical and histological observations of Marchesani are important, but they lack colloid-chemical proof. Discussing this we may say that many years ago M. H. Fischer and Marion Hook had already proved that the absorption of water by nervous tissues represents a real swelling. From our papers it looks as if the optic nerve, its sheaths and the retina are also tissues which have the possibility of swelling. Thus a theory of papilloedema founded upon swelling of brain and optic nerve, as has been given by Marchesani and Spatz, might be possible. Only one has to be on the outlook for facts which would directly contradict such a theory.

There is another experiment which is in favour of Marchesani's views though it has not been mentioned by him. In fresh cases of papilloedema no signs of inflammation are found. Neither is a real oedema present i.e., in no case is water found, the tissues are swollen but no water can be traced between the tissues.

Furthermore it is not possible to obtain a papilloedema by increasing the intra-cranial pressure, as latelv has been proved very clearly by Lindberg. He took rabbits and kept their intra-cranial 
pressure for 3 hours at $40 \mathrm{~mm}$. $\mathrm{Hg}$; then until their death he increased the pressure to $60-80 \mathrm{~mm}$. Hg. By doing so he did not get a papilloedema though the veins were wider and the arteries narrower.

On the other hand it was found by Bauermann and Sobansky that the pressure in the veins of the retina is caused by the intracranial pressure. Moreover that papilloedema can be found only when there is an abnormal relation between the arterial and venous pressure of the vessels of the retina. In this way Sobansky succeeded in getting temporarily a papilloedema in a dog. By stopping in a dog the venous outlet of the optic nerve without interfering with the arterial supply i.e., by changing the relation in pressure in the vessels of the retina without changing the intra-cranial pressure he was able to observe after 3 minutes the beginning of a hyperaemia of the papilla and after 6 more minutes a swelling of the papilla. Are there now any relations between these changes in pressure and the absorption of water ?

It is shown that in every case changes in pressure are the primum movens, that rather considerable changes in pressure are necessary to cause some effect, and that the change in pressure must last for some time before a papilloedema is obtained.

Sobansky found that the changes in pressure represented an approach of the different pressures to each other. Thus they lead to a stasis of venous blood and consequently to a retardation of the metabolism. This causes different changes and the result might be that there is an increase in the amount of swelling of the tissues. Such a process takes time. Therefore it is not seen immediately at the beginning of the experiment or the disease. As long as there is only swelling of no excessive degree the function remains relatively good. As is the case in all swelling phenomena these processes are reversible, so it appears to be quite possible to connect and complete the theories of Marchesani and of Bauermann and Sobansky with each other. The latter is not able to explain why changes in pressure lead to a choked disc, and the first is not capable of explaining the relations between changes in pressure and papilloedema. Nevertheless Marchesani's theory is the more important of the two. For, having first stated that the condition of the part of the optic nerve which can be seen by the ophthalmoscope depends on its degree of swelling, it is easy to explain the opposite condition i.e., an atrophy of the papilla by decrease of the swelling, from the same point of view. Marchesani indeed has already discussed the possibility that those cases which have been described by Thiel, and in which pale discs containing an excavation were seen, might have been caused not by atrophy but by a change in the water percentage of the tissues. 
Various other examples might be given, illustrating relations between colloid-chemical researches and clinical problems e.g., atrophies by pressure, condition of the disc in the Foster-Kennedy syndrome etc.

\title{
Summary
}

Researches are made on the water-binding of the optic nerve and on that of its sheaths, and it is proved that these tissues have the possibility of swelling. The capacity and intensity of the waterbinding of the optic nerve is much greater than that of the retina. Moreover the water-binding of the optic nerve is of a different type from that of the retina. The conditions of water-binding are the same in the sheaths of the optic nerve as in the sclera. Furthermore the clinical significance of the water-binding of the optic nerve and its sheaths is discussed and some remarks are made on the theories of the genesis of papilloedema.

\section{REFERENCES}

Bauermann-Ber. d. deutsch. ophthal. Ges., p. 53, 1925

F. P. Fischer -Arch. f. Augenheilk., Vol. CIII, p. 1, 1930.

J. A. van Heuven and F. P. Fischer.-Brit. Jl. of Ophthal., Vol. XIX, p. 390, 1935.

M. O. Hooker and M. F. Fischer.-Kolloid-Zeitschr., Vol. X, p. 283, 1912.

Lauber, J.-Wien. klin. Wochenschr., Vol. LI, p. 1, 1934

Lindberg, J. G.-Finska Läk. sällsk., Vol. LXXVI, p 694, 1934.

Marchesani, O.-Ber. d. deutsch. ophthal. Ges., p. 157, 1930 ; p. 356, 1934.

Sobanski.-Kl. Ozcna, p. 360, 1933.

Thiel.-Ber.d. deutsch. ophthal. Ges., p. 133, 1930.

\section{ON THE SCIENTIFIC AND PRACTICAL VALUE OF IONIZATION IN OPHTHALMOLOGY. RECENT ADVANCES AND RESEARCHES}

BY

\author{
Dr. Gustav ERLANGer \\ NEW YORK
}

IONIZATION-the introduction of drugs and electrolytes into the tissues of the human body or into those of the body of animals with the aid of a weak direct current-plays an important rôle in recent medical literature. This method has been studied especially in ophthalmology. And here its great therapeutic effect may be explained either by experiment or by clinical experience.

The pharmaco-dynamic effect of the current plus the electrolyte consists in a sudden alteration of the permeability of the tissues and with it also of the surface tension. We fix the electrolytes somewhat longer to the cells, we are able to irritate the sympathetic 